\title{
Changes of resistome, mobilome and potential hosts of antibiotic resistance genes during the transformation of anaerobic digestion from mesophilic to thermophilic
}

\author{
Zhe Tian $^{\text {a, c }}$, Yu Zhang ${ }^{\text {a, c, * }}$, Bo Yu ${ }^{\text {b }}$, Min Yang ${ }^{\text {b, c }}$ \\ ${ }^{\text {a }}$ Key Laboratory of Drinking Water Science and Technology, Research Center for Eco-Environmental Sciences, Chinese Academy of Sciences, Beijing, 100085, \\ China \\ b State Key Laboratory of Environmental Aquatic Chemistry, Research Center for Eco-Environmental Sciences, Chinese Academy of Sciences, Beijing, 100085, \\ China \\ ${ }^{\mathrm{c}}$ Beijing Key Laboratory of Industrial Wastewater Treatment and Resource Recovery, Research Center for Eco-Environmental Sciences, Chinese Academy of \\ Sciences, Beijing, 100085, China
}

\section{A R T I C L E I N F O}

\section{Article history:}

Received 22 January 2016

Received in revised form 7 April 2016

Accepted 13 April 2016

Available online 16 April 2016

\section{Keywords:}

Antibiotic resistance gene

Mobilome

Network analysis

Transformation

Anaerobic digestion

\begin{abstract}
A B S T R A C T
This study aimed to reveal how antibiotic resistance genes (ARGs) and their horizontal and vertical transfer-related items (mobilome and bacterial hosts) respond to the transformation of anaerobic digestion (AD) from mesophilic to thermophilic using one-step temperature increase. The resistomes and mobilomes of mesophilic and thermophilic sludge were investigated using metagenome sequencing, and the changes in 24 representative ARGs belonging to three categories, class 1 integron and bacterial genera during the transition period were further followed using quantitative PCR and 454pyrosequencing. After the temperature increase, resistome abundance in the digested sludge decreased from $125.97 \mathrm{ppm}$ (day 0, mesophilic) to $50.65 \mathrm{ppm}$ (day 57, thermophilic) with the reduction of most ARG types except for the aminoglycoside resistance genes. Thermophilic sludge also had a smaller mobilome, including plasmids, insertion sequences and integrons, than that of mesophilic sludge, suggesting the lower horizontal transfer potential of ARGs under thermophilic conditions. On the other hand, the total abundance of 18 bacterial genera, which were suggested as the possible hosts for 13 ARGs through network analysis, decreased from $23.27 \%$ in mesophilic sludge to $11.92 \%$ in thermophilic sludge, indicating fewer hosts for the vertical expansion of ARGs after the increase in temperature. These results indicate that the better reduction of resistome abundance by thermophilic AD might be associated with the decrease of both the horizontal and vertical transferability of ARGs.
\end{abstract}

(c) 2016 Elsevier Ltd. All rights reserved.

\section{Introduction}

Many studies have demonstrated that sewage sludge from municipal wastewater treatment plants (WWTPs) is an important reservoir for antibiotic resistance genes (ARGs) (Auerbach et al., 2007; Munck et al., 2015). For example, six tetracycline resistance genes $(\operatorname{tet}(\mathrm{A}), \operatorname{tet}(\mathrm{C}), \operatorname{tet}(\mathrm{G}), \operatorname{tet}(\mathrm{M}), \operatorname{tet}(\mathrm{S})$, and $\operatorname{tet}(\mathrm{X}))$ have been detected in the sewage sludge of 15 WWTPs from different regions (Zhang and Zhang, 2011), and 140 antibiotic resistance

\footnotetext{
* Corresponding author. Key Laboratory of Drinking Water Science and Technology, Research Center for Eco-Environmental Sciences, Chinese Academy of Sciences, Beijing, 100085, China.

E-mail address: zhangyu@rcees.ac.cn (Y. Zhang).
}

determinants including the recently described clinically relevant resistance genes (aadA6, imp-9, qnrB1, etc.) were identified in the plasmid metagenome of activated sludge bacteria (Szczepanowski et al., 2009). Thus, excess sewage sludge should be handled properly to prevent the release of ARGs into the environment.

Recently, the effectiveness of anaerobic digestion (AD), which is a widely applied technology for the disposal of excess sludge (Appels et al., 2008), in mitigating the quantities of ARGs in sewage sludge was also noticed. Using quantitative polymerase chain reaction (qPCR), Ghosh et al. (2009a) found that full-scale thermophilic digestion showed better reduction in three tetracycline resistance genes $(\operatorname{tet}(\mathrm{A}), \operatorname{tet}(\mathrm{O})$, and tet $(\mathrm{X}))$, and class 1 integron (intI1), an important mobile element for horizontal ARG transfer, than the more widely applied mesophilic digestion. Similar results were confirmed in lab-scale studies by Diehl and LaPara (2010). 
However, subsequent research targeting other resistant determinants found that the benefits of thermophilic digestion might not be universal (Ma et al., 2011). Recently, metagenomic analysis was applied and revealed that thermophilic sludge had a slightly lower resistome than that of mesophilic sludge (Zhang et al., 2015). Recent studies also showed that the combination of metagenomics and qPCR might provide a more comprehensive and quantitative insight into the dynamics of microbial population and ARGs during wastewater and sludge treatment (Aydin et al., 2015; Zhang et al., 2015; Ju et al., 2016).

Despite the above efforts, the mechanisms behind the reduction of ARGs during mesophilic and thermophilic processes are not well explored or understood. ARGs proliferate mainly through two processes: vertical gene transfer attributed to the reproduction of bacterial hosts, and horizontal gene transfer attributed to the transfer of ARGs between different bacterial cells via mobile elements (Sorensen et al., 2005). Because of the decrease of intI1 during $\mathrm{AD}$, the reduction of ARGs has been speculated to be associated with the blockage of their horizontal transfer pathways (Diehl and LaPara, 2010; Ma et al., 2011). Although suggested as an indicator of horizontal gene transfer potential (Ma et al., 2011), intI1 is not mobile in its own right and does not contain many important ARGs such as tet genes (Toleman et al., 2006). Thus, other mobile elements including plasmids and transposons should be investigated to validate the speculation. On the other hand, recent studies have shown that bacterial communities structured soil and sludge resistomes (Forsberg et al., 2014; Su et al., 2015). Considering the completely different bacterial populations in mesophilic and thermophilic digestion sludge (Ma et al., 2011; Tian et al., 2015), disturbance of the vertical transfer pathway might also be an important factor of ARG reduction. Thus, simultaneously exploring the responses of ARGs and their horizontal and vertical transferrelated items (mobilome and bacterial hosts) to shifts in digestion temperature might be helpful in revealing the mechanisms of ARGs reduction.

In our previous study, an anaerobic thermophilic digester was successfully started up to treat excess sewage sludge from a mesophilic one using the strategy of one-step temperature increase (Tian et al., 2015). Here, metagenomics and quantitative PCR were jointly used to reveal the comprehensive profiles of ARGs in digested sludge before and after temperature increase and the fates of 24 antibiotic resistance determinants and intI 1 over the transition period. Changes in mobilome, distribution of ARGs in plasmids and co-occurrence patterns between ARGs and bacterial taxa were also analyzed. This work provides scientific support for controlling the spread of ARGs in the environment.

\section{Material and methods}

\subsection{Reactor setup and transition from mesophilic to thermophilic $A D$}

This experiment was carried out in one completely stirred tank reactor (CSTR) with $8 \mathrm{~L}$ total volume and $6 \mathrm{~L}$ working volume. The CSTR was operated at a constant feed rate of $300 \mathrm{~mL} /$ day and solid retention time (SRT) of 20 days. Substrate, a mixture of primary and secondary sludge collected from Gaobeidian WWTP, was fed into the reactor once a day. The reactor was operated under mesophilic conditions $\left(35^{\circ} \mathrm{C}\right)$ for more than 100 days before the temperature was increased to $55{ }^{\circ} \mathrm{C}$ in one step and then maintained under thermophilic conditions for two months. The detailed operation conditions of the reactor and the anaerobic digestion performance are described in previous research (Tian et al., 2015).

\subsection{Sample collection and DNA extraction}

Digested sludge samples of Day 0, 4, 11, 18, 26, 34, 44, and 57 after temperature increase and excess sewage sludge samples of Day $0,11,34$ and 57 were taken from the reactor for DNA extraction. Each sludge sample $(1 \mathrm{~mL})$ was centrifuged at $10,000 \mathrm{rpm}$ for $10 \mathrm{~min}$ at $4{ }^{\circ} \mathrm{C}$, and the resulting sediment was used for DNA extraction using FastDNA ${ }^{\circledR}$ SPIN kit for soil (Qbiogene, Solon $\mathrm{OH}$, USA) according to the manufacturer's instructions. For each sample, DNA was extracted in duplicate to avoid bias, and extracts from the same sample were pooled. Concentrations and quality of the extracted DNA were checked by spectrophotometric analysis on a NanoDrop ND-1000 (Nanodrop, USA) and electrophoresis on a 1\% (weight/volume) agarose gel. Due to the stable composition of the sewage sludge over the experimental period (data not shown), four DNA samples of sewage sludge were mixed equally for subsequent molecular analysis.

\subsection{4 pyrosequencing of bacterial communities}

For 454-pyrosequencing, bacterial 16S rRNA genes in nine sludge samples were amplified with primers $27 \mathrm{~F}\left(5^{\prime}\right.$-AGAGTTTGATCCTGGCTCAG-3') and 534R (5'-TTACCGCGGCTGCTGGCAC-3') (Koike et al., 2007). Barcodes that allow sample multiplexing during pyrosequencing were incorporated between the 454 adapter and the forward primers. The length of the amplicon, including the barcode and 454 primers, was $~ 596$ nt. The PCR amplification system and program are described in detail in previous work (Tian et al., 2015). The PCR products were purified and then sequenced by pyrosequencing using a 454 Life Sciences Genome SequencerFLX (Roche Diagnostics, Indianapolis, IN, USA). Raw pyrosequencing data were deposited in the NCBI Sequence Read Archive with accession no. SRP049225 (http://www.ncbi.nlm.nih. gov/Traces/sra/sra.cgi?study=SRP049225). After sequencing, the sequence reads were analyzed using Mothur software (Tian et al., 2015).

\subsection{Quantitative PCR assay}

Nine tetracycline resistance genes including four efflux genes (tet $(\mathrm{A})$, tet $(\mathrm{C})$, tet $(\mathrm{G})$, tet $(\mathrm{L}))$, four ribosomal protection protein genes $(\operatorname{tet}(\mathrm{Q}), \operatorname{tet}(\mathrm{O}), \operatorname{tet}(\mathrm{M}), \operatorname{tet}(\mathrm{W}))$ and one inactivating enzyme gene (tet $(\mathrm{X})$ ), seven macrolide resistance genes including four rRNA methylase genes (erm(B), $\operatorname{erm}(\mathrm{F}), \operatorname{erm}(\mathrm{T}), \operatorname{erm}(\mathrm{X}))$, one efflux gene $(\operatorname{mef}(\mathrm{A}))$, one esterase gene $(\operatorname{ere}(\mathrm{A}))$ and one phosphorylase gene $(M p h(B))$, eight aminoglycoside resistance genes including two acetyltransferases genes (aac(3)-II, aacA4), three nucleotidyltransferase genes ( $a a d A, a a d B$ and $a a d E)$, and three phosphotransferases genes (aphA1, strA and strB), one mobile element (intI1) and the 16S rRNA gene for domain bacteria were quantified using SYBR-Green real-time qPCR. The specificities of the used primer sets (Table S1) have been validated in recently published papers (Ma et al., 2011; Liu et al., 2012, 2014; Aydin et al., 2015) and verified in this study. Standard plasmids carrying target genes were obtained by TA clones and extracted using a TIANpure Mini Plasmid kit (Tiangen, China). Concentrations of the standard plasmids (ng/ $\mu \mathrm{L}$ ) were determined with the Nanodrop ND-1000 (Nanodrop, USA), and their copy concentrations (copies $/ \mu \mathrm{L}$ ) were then calculated (Pei et al., 2006). The $25 \mu \mathrm{L}$ reactions typically contained $1 \times$ Sybr Green I, $1 \times$ Dye (Takara), $200 \mathrm{nM}$ each primer, $0.5 \mathrm{mg} / \mathrm{mL}$ $\mathrm{BSA}$, and $2 \mu \mathrm{L}$ DNA templates. Real-time PCR was run using an ABI 7300 apparatus (ABI, USA) by the following program: $95^{\circ} \mathrm{C}$ for $30 \mathrm{~s}$, 40 cycles consisting of: (i) $95^{\circ} \mathrm{C}$ for $10 \mathrm{~s}$, (ii) annealing temperature for $15 \mathrm{~s}$ (Table S1), (iii) $72^{\circ} \mathrm{C}$ for $15 \mathrm{~s}$, and (iv) $78^{\circ} \mathrm{C}$ for $26 \mathrm{~s}$ to collect the fluorescent signals. The melting process was automatically 
generated using ABI 7300 software. Serial dilutions of the standard plasmids were used as calibration standards. Standard curves were constructed in each PCR run and the copied numbers of the genes in each sample were interpolated using these standard curves. All standards, samples, and negative control (sterile water) were quantified in triplicate. To prevent the inhibition of the sample matrix, 10-100-fold diluted samples were used for quantification.

The following requirements were satisfied to obtain reliable quantification (Table S2): $\mathrm{R}^{2}$ was higher than 0.99 for standard curves over five orders of magnitude. Amplification efficiencies based on slopes were between $90 \%$ and $110 \%$. The specificity was assured by the melting curves and gel electrophoresis. The minimum detection limits for all genes were in the range of $1.1 \times 10^{2}$ to $1.4 \times 10^{3}$ copies per $\mu$ L DNA. To minimize the variances caused by differences in bacterial abundance, DNA extraction and quantification efficiencies, relative abundances of ARGs and intI1 were used by normalizing their copy numbers to those of the bacterial $16 \mathrm{~S}$ rRNA genes for comparison (Figs. S1-S3, Table S3). Absolute abundance on a per sludge volume basis is shown in Table S4.

\subsection{Network analysis}

To visualize the correlations between ARGs and bacterial taxa, 24 ARGs quantified by qPCR and 474 bacterial genera identified by pyrosequencing were combined, and a co-occurrence network was constructed by the random matrix theory-based network inference method across eight digested sludge samples (Deng et al., 2012). First, a correlation matrix was constructed by calculating all possible pairwise Pearson correlations between the 498 items that occurred in at least five samples. The correlation matrix was then converted into the similarity matrix by taking absolute values (Horvath and Dong, 2008). Thereafter, a series of thresholds from 0.30 to 1.00 with 0.01 intervals were applied to the matrix, and only the similarity values above a certain threshold were kept for calculating matrix eigenvalues. The finest threshold was chosen when the nearest neighbour spacing distribution of eigenvalues followed Poisson distribution, which represents specific and nonrandom properties of complex systems (Deng et al., 2012), and meanwhile the threshold should be as low as possible (Deng et al., 2016). Network analyses were performed using an online analysis pipeline at http://ieg2.ou.edu/MENA. Network visualization was conducted on the interactive platform of Cytoscape (version 3.2.0).

\subsection{Illumina high-throughput sequencing}

Approximately $5 \mu \mathrm{g}$ of DNA of digested sludge samples on day 0 (Meso-d0) and day 57 (Thermo-d57) was used for library construction and sequencing. High-throughput sequencing was conducted at Novogene (Beijing, China) using Illumina Hiseq 2500 with the sequencing strategy of index PE125 $+8+125$ cycle (Paired-End sequencing, 125-bp reads and 8-bp index sequence). Approximately $5 \mathrm{~Gb}$ of data was generated for each sample. The raw Illumina read data of the two samples has been deposited in the European Nucleotide Archive, under the accession PRJEB13054 (http://www.ebi.ac.uk/ena/data/view/PRJEB13054). An online tool kit (Galaxy, https://usegalaxy.org/) was utilized to filter low quality reads to ensure (1) less than three ambiguous nucleotides in one read; (2) more than $90 \%$ bases with quality score greater than 30 ; and (3) no sequencing artifacts (Miao et al., 2015).

A local database of resistances genes was created by downloading all sequences from the Antibiotic Resistance Genes Database (ARDB) (http://ardb.cbcb.umd.edu/), and the redundant sequences from the downloaded database were removed using a customized script as well as manual checking. The nonredundant ARDB contains about 3000 sequences. All quality-filtered reads of the two samples were searched for ARGs against the nonredundant ARDB using BLASTx with E-value $\leq 10^{-5}$ (Yang et al., 2013). A read was annotated as an ARG-like fragment according to its best BLASTx hit if the hit had a sequence similarity of above $90 \%$ over an alignment of at least 25 amino acids (Kristiansson et al., 2011). Local databases of insertion sequences (ISs), integrons and plasmids were separately created by downloading ISs sequences from the ISfinder (https://www-is.biotoul.fr/), integrase genes from the INTEGRALL (http://integrall.bio.ua.pt/) and plasmid sequences from the NCBI plasmid genome database (ftp://ftp.ncbi.nih.gov/genomes/ Plasmids/). Sequences belonging to plasmid, integron- or IS-like sequences were identified by aligning the sequences against the three mobile genetic elements databases using BLASTx with an Evalue cut-off of $10^{-5}$ and then filtered using the same conditions as ARG identification. The levels of ARGs or mobile element-like sequences in the present study were described using the unit of "ppm" (one read in one million reads) as recommended by Yang et al. (2013), which was defined as the portion of ARG or mobile element-like sequences in "total metagenome sequences".

To explore the distribution of ARGs on plasmids, all clean reads were assembled using Velvet with 51-subunit Kmers. The obtained contigs of each sludge sample were aligned using BLASTx and compared with ARDB using an E-value $\leq 10^{-5}$, and filtered using cut-offs at identity $\geq 90 \%$ and alignment length $\geq 25$ aa. Then, the contigs that carried ARG-like fragments were further aligned against the local plasmid genome database using BLASTn with Evalue $\leq 10^{-5}$ and then filtered using the conditions described above.

\subsection{Statistical analysis}

Pair-sample $t$-tests were conducted using Origin 8.0 to determine whether qPCR-based ARGs and intI1 abundances were significantly different between samples. A $p$-value of $<0.05$ was considered significant. Pearson's bi-variate correlation analysis was performed using SPSS 15.0 to assess correlations between ARGs and intI1.

\section{Results}

\subsection{Resistomes and mobilomes of digested sludge before and after temperature increase}

As described in our previous study, the thermophilic microbial community was established in 20 days after the increase in temperature from $35{ }^{\circ} \mathrm{C}$ to $55{ }^{\circ} \mathrm{C}$ (Tian et al., 2015). So, two digested sludge samples, one representing the mesophilic community and another representing the thermophilic community, were taken on day 0 and day 57, respectively. The ARG profiles of the two samples were revealed using the metagenomic approach, as shown in Fig. 1. A total of 13 types of ARGs were detected in mesophilic sludge (day 0 ), with 9 types of ARGs having an abundance over $1 \mathrm{ppm}$. Tetracycline (47.96 ppm), sulfonamide (23.09 ppm) and macrolidelincosamide-streptogramin (MLS) (13.88 ppm) resistance genes were the three dominant types in mesophilic sludge, followed by those for aminoglycoside (12.73 ppm), chloramphenicol (9.09 ppm), multidrug (8.90 ppm) and quinolone (3.60 ppm) (Fig. 1a). The total ARG abundance decreased from $125.97 \mathrm{ppm}$ in mesophilic sludge (day 0) to $50.65 \mathrm{ppm}$ in thermophilic sludge (day 57). The abundances of the three dominant resistance genes decreased to $11.73,5.81$ and $5.99 \mathrm{ppm}$, respectively, in thermophilic sludge, and chloramphenicol, multidrug, quinolone, fosmidomycin and trimethoprim ARGs also decreased by close to or above $50 \%$. Beta-lactam and bacitracin ARGs were only slightly reduced by $1.83 \%$ and $9.92 \%$, respectively, while aminoglycoside resistance genes slightly increased from $12.73 \mathrm{ppm}$ to $13.39 \mathrm{ppm}$ after the 
(a)

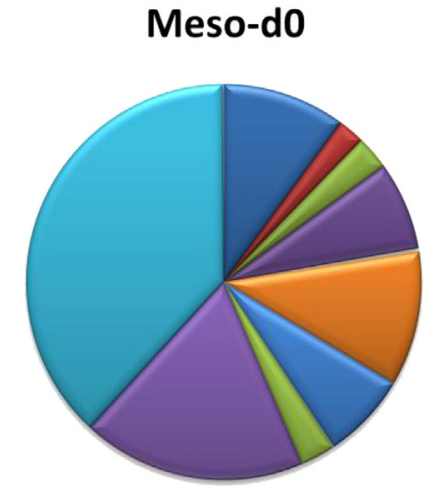

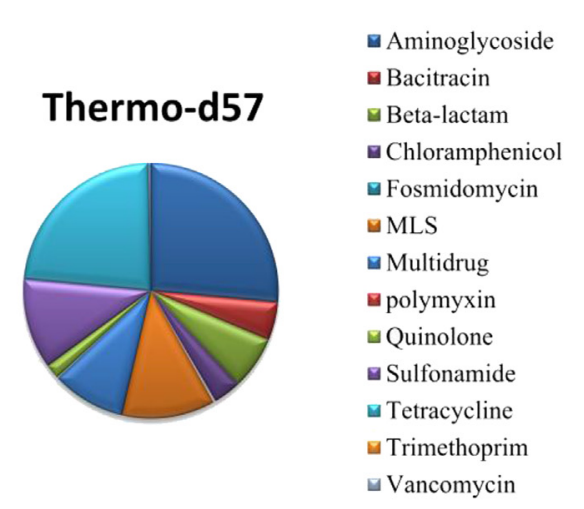

Aminoglycoside

Bacitracin

Beta-lactam

Chloramphenicol

$\square$ Fosmidomycin

$\square$ Tetracycline

$\square$ Vancomycin

(b)

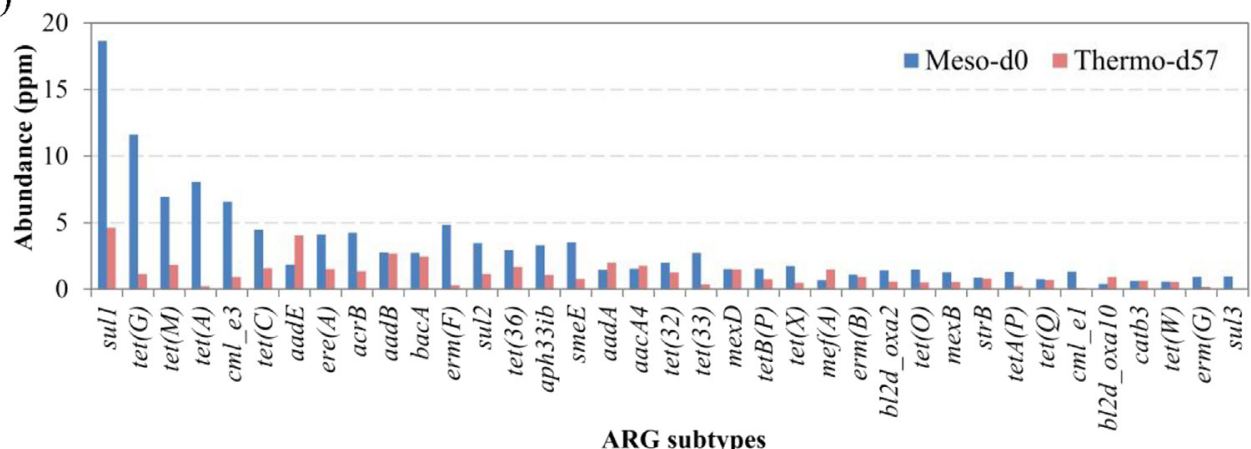

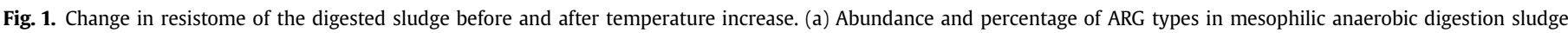

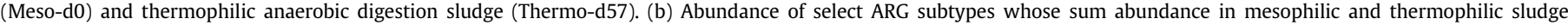
$>1 \mathrm{ppm}$.

hike of temperature, becoming the most dominant resistance gene type in thermophilic sludge (Fig. 1a). Though the polymyxin and vancomycin ARGs were enriched by $21.23 \%$ and $182.88 \%$, respectively, their abundances were very low $(<0.2 \mathrm{ppm})$.

A total of 125 ARG subtypes were detected in the two samples, and the abundances of 37 ones with their individual sum in mesophilic and thermophilic sludge $>1 \mathrm{ppm}$ are compared in Fig. $1 \mathrm{~b}$. Among the 37 subtypes, 31 were reduced after temperature increase. sul1, the most dominant subtype in mesophilic sludge, several tet genes $(\operatorname{tet}(\mathrm{G})$, tet $(\mathrm{M})$, tet $(\mathrm{A})$, tet( $\mathrm{C})$ and tet(36)), chloramphenicol efflux pump gene $\mathrm{cml} \_3$ and erythromycin esterase gene ere (A) decreased by 42.90-97.15\%. However, six ARG subtypes (aadE, aadA, aacA4, mef(A), bl2d_oxa10 and catb3) in digested sludge were enriched by $2.86-130.92 \%$ after the temperature increase.

Search in INTEGRALL database revealed that a total of 230 types of known integron related genes were matched with 192 in mesophilic sludge and 170 in thermophilic sludge, which all belonged to intI1. As shown in Fig. 2 and S4, the abundance of integrons decreased from 123.45 to $70.48 \mathrm{ppm}$ after temperature increase.

Alignment against the ISfinder database showed that a total of 1045 types of known ISs, which can be further classified into 25 IS families, were detected with 814 in mesophilic sludge and 782 in thermophilic sludge. After temperature increase, their sum abundance decreased from 528.73 to $391.36 \mathrm{ppm}$ (Fig. 2). IS256 (134.15 ppm), IS3 (110.73 ppm) and Tn3 (100.76 ppm) were the dominant IS families in mesophilic sludge, accounting for over $65 \%$ of the total IS abundance. After the temperature hike, the abundances of IS256 and IS3 decreased to 42.13 and $48.77 \mathrm{ppm}$, respectively, while $\mathrm{Tn} 3$ slightly increased (4.01\%) (Fig. S5).

Totally 1554 types of plasmid related genes were identified by searching the NCBI Plasmid Genome Database, with 1298 in mesophilic sludge and 1282 in thermophilic sludge, and the total abundance decreased from 2984.82 to 2347.47 ppm after temperature increase (Fig. 2). The dominant plasmids in mesophilic sludge were pTM3, plasmid CRM-0020, plasmid WSH-002_p1, pPRO2, pECD227_112 and pGBRO01. The abundances of pPRO2, pECD227_112 and pGBRO01 decreased by 54.29, 69.93 and $99.83 \%$, respectively, while those of pTM3 and plasmid CRM-0020 remained almost unchanged, and plasmid WSH-002_p1 increased from 80.74 to $139.54 \mathrm{ppm}$ in thermophilic sludge (Fig. S6).

To investigate the distribution of ARGs on plasmids, the presence of ARG sequences bearing contigs on plasmids were analyzed (Tables S5 and S6). A total of 41 contigs associated with 20 resistance subtypes were found to be on 25 plasmids in mesophilic sludge (Table S6). Among the 20 ARG subtypes, aadB, cml_e1, ereA, sul1, tet(33), tet $(\mathrm{G})$, tet $(\mathrm{M})$ and $\operatorname{tet}(\mathrm{W})$ were simultaneously carried by two or three different plasmids. Moreover, plasmid p1 from Klebsiella pneumoniae JM45 and p3 from Enterococcus faecium Aus0085 contained two resistance subtypes, while pECD227_112 contained three ARGs (sul1, tet(A) and aadA) (Table S5). By comparison, only 14 contigs associated with 11 ARGs were identified on 13 plasmids on day 57 . Among the resistance subtypes detected in thermophilic sludge, ereA, sul2 and tet(C) were located on two different plasmids, and only pNDMCFuy from Citrobacter simultaneously contained two resistance subtypes (tet(C) and bl2d_oxa10) (Table S6).

\subsection{Changes in 24 ARGs and intI1 over the sludge transformation period}

Twenty-four ARGs belonging to three ARG types and intI1, which were detected in sludge resistome and mobilome, were further quantified by qPCR over the sludge transformation period. As 


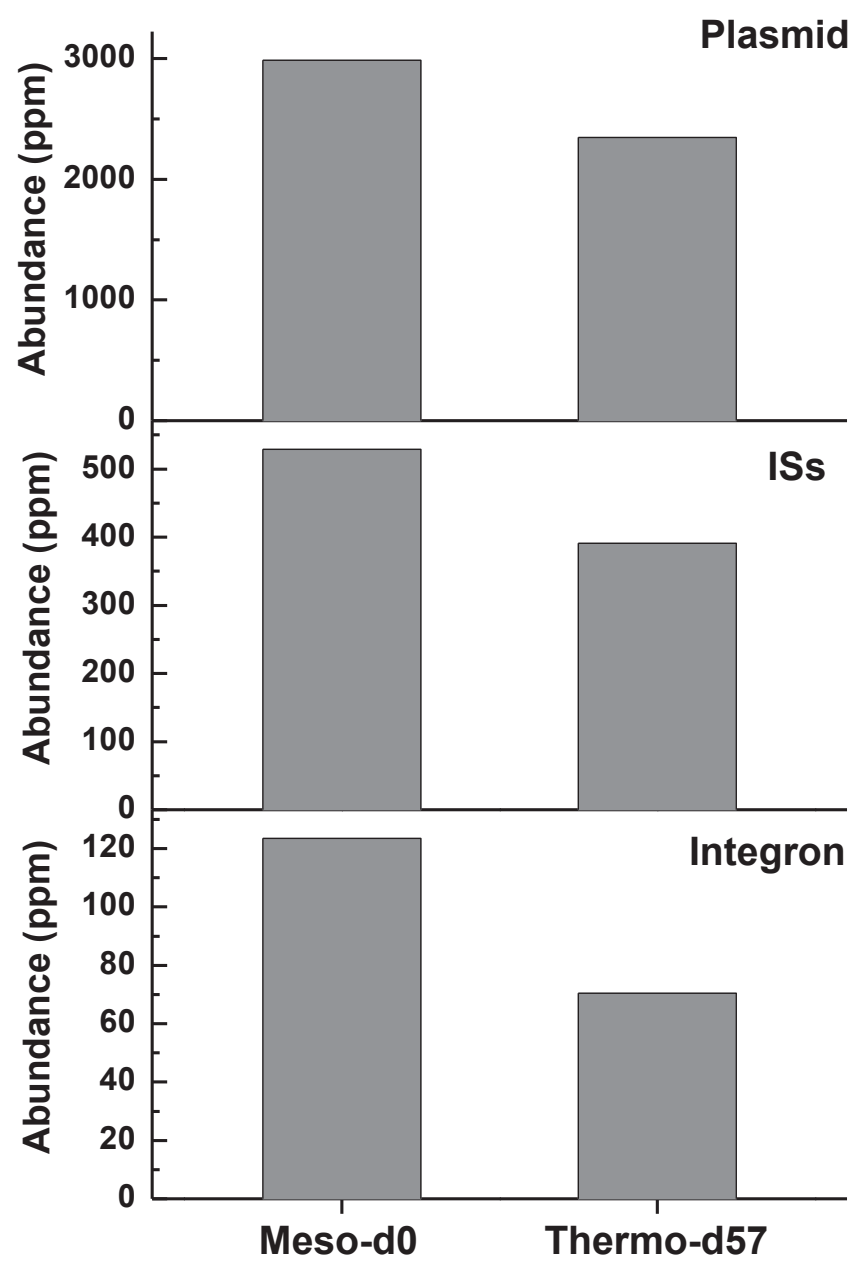

Fig. 2. Change in mobilome of the digested sludge before and after temperature increase.

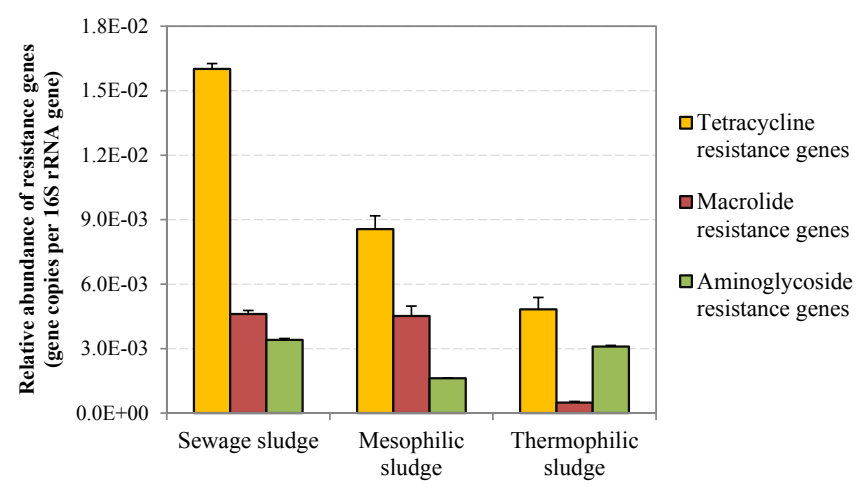

Fig. 3. Total abundances of tetracycline, macrolide and aminoglycoside resistance genes in sewage sludge, mesophilic sludge (Day 0) and thermophilic sludge (Day 57) quantified by qPCR.

shown in Fig. 3, the feed sludge exhibited high total ARG relative abundance $\left(2.40 \times 10^{-2}\right.$; relative to $16 \mathrm{~S}$ rRNA), with total abundances of tetracycline, macrolide and aminoglycoside resistance genes being $1.60 \times 10^{-2}, 4.61 \times 10^{-3}$ and $3.40 \times 10^{-3}$, respectively. The levels of the first two types of ARGs were in accordance with those reported in previous studies (Liu et al., 2012, 2014), while the relative abundances of the eight aminoglycoside resistance genes in sewage sludge were quantified for the first time. As shown in Table S3, the relative abundances of the individual ARGs in the feed sludge ranged from $10^{-6}$ to $10^{-3}$, with tet(A) $\left(6.59 \times 10^{-3} \pm 5.71 \times 10^{-4}\right)$ being the most abundant and aphA1 $\left(6.48 \times 10^{-6} \pm 3.98 \times 10^{-7}\right), \operatorname{Mph}(\mathrm{B})\left(6.20 \times 10^{-6} \pm 9.42 \times 10^{-8}\right)$ and $\operatorname{mef}(\mathrm{A})\left(4.39 \times 10^{-6} \pm 1.55 \times 10^{-7}\right)$ being the rarest.

The sum of the relative abundances of the 24 ARGs in the feed sludge decreased by $38.82 \%$ and $64.99 \%$ after mesophilic and thermophilic AD treatment, respectively. After temperature increase, the reduction rates of tetracycline and macrolide resistance genes increased from $46.53 \%$ to $69.84 \%$ and $1.98 \%$ to $89.45 \%$, respectively, while that of aminoglycoside resistance genes decreased from $52.46 \%$ to $9.05 \%$ (Fig. 3). The changes in individual ARGs over the transition period are shown in Figs. S1-S3. According to their profiles on day 0 (mesophilic digestion) and day 57 (thermophilic digestion), the 24 detected ARGs could be divided into three categories (Table 1$)$. Except for tet(L) in mesophilic AD $(P=0.054)$ and aadA in thermophilic $\mathrm{AD}(P=0.087)$, significantly reduced $A R G s$ under both $A D$ conditions $(P<0.05)$ included tet $(A)$, $\operatorname{tet}(\mathrm{C}), \operatorname{tet}(\mathrm{G}), \operatorname{tet}(\mathrm{L}), \operatorname{tet}(\mathrm{O}), \operatorname{tet}(\mathrm{M}), \operatorname{tet}(\mathrm{Q}), \operatorname{tet}(\mathrm{W}), \operatorname{tet}(\mathrm{X}), \operatorname{erm}(\mathrm{B})$, $\operatorname{erm}(\mathrm{T}), \operatorname{erm}(\mathrm{X}), \operatorname{aac}(3)-I I, \operatorname{aacA4}, \operatorname{aad} A, \operatorname{aadB}, \operatorname{aph} A 1$, strA, and strB; ARGs that significantly increased in mesophilic $\mathrm{AD}(P<0.05)$, but decreased in thermophilic $\mathrm{AD}(P<0.05)$ included ermF and ereA; ARGs that decreased in mesophilic $\operatorname{AD}(P<0.01)$, but increased in thermophilic $\mathrm{AD}(P<0.05)$ included $m p h(\mathrm{~B})$, mef(A), and aadE.

Feed sludge also had a high level $\left(7.89 \times 10^{-2} \pm 6.62 \times 10^{-3}\right)$ of intI1, which was in accordance with previous studies (Diehl and LaPara, 2010; Ma et al., 2011). Its abundance decreased by $47.51 \%$ $(P<0.05)$ and $71.90 \%(P<0.01)$ after mesophilic and thermophilic $\mathrm{AD}$, respectively (Table 1 ). As shown in Table S7, among the 24 ARGs detected, only tet $(A)$, tet $(\mathrm{G})$, and tet $(\mathrm{Q})$ displayed a positive correlation with intI1 $(P<0.05)$ during the transition period.

Table 1

Reduction of 24 ARGs and intI1 in sewage sludge by mesophilic (Day 0) and thermophilic (Day 57) AD detected by qPCR.

\begin{tabular}{|c|c|c|c|}
\hline \multirow[t]{2}{*}{ Resistance genes } & & \multicolumn{2}{|c|}{ Removal rate $(\%)^{\mathrm{a}}$} \\
\hline & & Mesophilic AD & Thermophilic AD \\
\hline \multirow[t]{9}{*}{ Tetracyclines } & $\operatorname{tet}(\mathrm{A})$ & 40.82 & 79.36 \\
\hline & $\operatorname{tet}(\mathrm{C})$ & 38.70 & 51.98 \\
\hline & $\operatorname{tet}(\mathrm{G})$ & 39.54 & 55.67 \\
\hline & $\operatorname{tet}(\mathrm{L})$ & 40.80 & 65.92 \\
\hline & $\operatorname{tet}(\mathrm{Q})$ & 88.99 & 86.45 \\
\hline & $\operatorname{tet}(\mathrm{O})$ & 21.71 & 67.58 \\
\hline & $\operatorname{tet}(\mathrm{M})$ & 47.41 & 65.71 \\
\hline & $\operatorname{tet}(\mathrm{W})$ & 82.50 & 81.14 \\
\hline & tet $(\mathrm{X})$ & 68.56 & 88.19 \\
\hline \multirow[t]{7}{*}{ Macrolides } & $\operatorname{erm}(\mathrm{B})$ & 90.03 & 95.75 \\
\hline & $\operatorname{erm}(\mathrm{F})$ & -104.99 & 93.06 \\
\hline & $\operatorname{erm}(\mathrm{T})$ & 93.49 & 89.48 \\
\hline & $\operatorname{erm}(\mathrm{X})$ & 88.29 & 84.82 \\
\hline & $m e f(\mathrm{~A})$ & 60.21 & -20.93 \\
\hline & $\operatorname{ere}(\mathrm{A})$ & -61.37 & 42.97 \\
\hline & $\operatorname{Mph}(\mathrm{B})$ & 52.23 & -40.56 \\
\hline \multirow[t]{8}{*}{ Aminoglycosides } & $\operatorname{aac}(3)-I I$ & 73.17 & 55.97 \\
\hline & aacA4 & 53.95 & 33.42 \\
\hline & $\operatorname{aad} A$ & 38.18 & 19.07 \\
\hline & $a a d B$ & 65.87 & 60.13 \\
\hline & aadE & 78.10 & -314.31 \\
\hline & aphA1 & 71.35 & 52.14 \\
\hline & strA & 55.88 & 44.14 \\
\hline & $s t r B$ & 57.44 & 40.27 \\
\hline intI1 & & 47.51 & 71.90 \\
\hline
\end{tabular}

a The removal rate (\%) is based on the difference in the individual resistance genes from the AD sludge vs. the sewage sludge (untreated). 


\subsection{Co-occurrence between 24 ARGs and bacterial taxa}

After the increase in temperature, both the abundance and diversity of the bacterial population in the digested sludge were decreased (Tian et al., 2015). To find the possible host information for individual ARGs, the co-occurrence patterns between the 24 ARGs and bacterial taxa during the transition period were investigated using network analysis (Fig. 4), based on the hypothesis that the significantly similar abundance trends among different samples was because of some specific bacterial taxa carrying some specific ARGs (Forsberg et al., 2014; Li et al., 2015). The detailed cooccurrence between ARGs and bacterial taxa is summarized in Table S8. As shown in Fig. 4 and Table S8, the total abundance of 18 bacterial genera, which were suggested as the possible hosts of 13 ARGs through network analysis, decreased from $23.27 \%$ in mesophilic sludge to $11.92 \%$ in thermophilic sludge. Bacteroides and Exilispira might be the hosts of tetracycline resistance gene tet(X), and Levilinea might contain another two tetracycline resistance genes (tet(A) and tet(G)). Ruminococcus, Ottowia, Gordonibacter and
Lautropia were found to be the hosts of four aminoglycoside resistance subtypes (strB, strA, aphA1 and $a a d B$ ), while another aminoglycoside nucleotidyltransferase gene aadE was mainly carried by Syntrophaceticus and Haloplasma. Diaphorobacter and Dechloromonas took along the MLS efflux gene (mef(A)), and EM3, a typical thermophilic genus (Hugenholtz et al., 1998), mainly carried the MLS phosphorylase gene $(M p h(B))$.

\section{Discussion}

The purpose of this study was to explore the mechanisms behind the reduction of ARGs during mesophilic and thermophilic AD processes. Different from previous studies that compared steady-state reactors operated in parallel (Ghosh et al., 2009a; Diehl and LaPara, 2010; Ma et al., 2011; Zhang et al., 2015), this study focused on the dynamic transition of an anaerobic digester from mesophilic steady-state to thermophilic one to reveal how resistance-related items (resistomes, mobilomes and bacterial hosts) in digested sludge respond to the increase of digestion

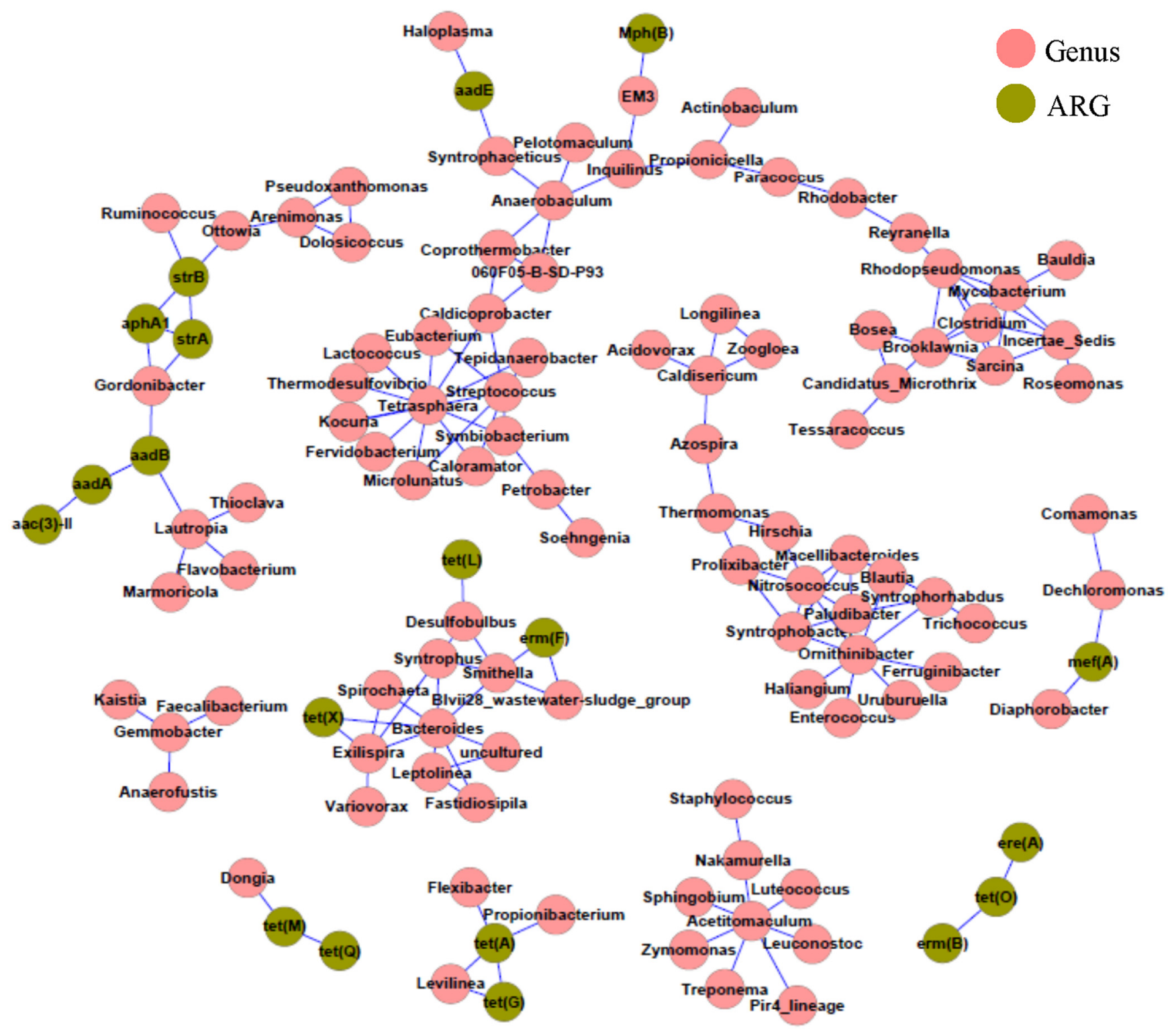

Fig. 4. Network analysis revealing the co-occurrence patterns between ARG subtypes and bacterial taxa during the transition period. 
temperature by jointly using metagenomics, qPCR and 454pyrosequencing. Previous study has demonstrated that the outputs from the qPCR and metagenomic analyses support the same results for detecting ARGs no matter in their total quantity or individual ARG abundance (Aydin et al., 2015). In this study, both metagenomic and qPCR analyses showed that thermophilic sludge held a lower overall ARG abundance than that of the mesophilic one (Figs. 1 and 3). Using parallel bench-scale reactors, Zhang et al. (2015) found that no measureable difference in the abundance of total ARGs in either thermophilic or mesophilic sludge treating the secondary sludge, which was not in accordance with this study. One of the possible reasons for the inconsistency might be the difference in feed sludge. Regarding individual ARGs, thermophilic AD showed better performance in the reduction of $\operatorname{acr} B$, tet( $(A), \operatorname{tet}(\mathrm{L})$, tet $(\mathrm{O})$, tet( $\mathrm{M})$, tet $(\mathrm{X}), \operatorname{sul} 1, \operatorname{erm}(\mathrm{B}), \operatorname{erm} F$ and $\operatorname{ere} A$, which was in accordance with previous studies (Ghosh et al., 2009a; Diehl and LaPara, 2010; Ma et al., 2011; Zhang et al., 2015). Mesophilic AD showed better performance in the reduction of aac(3)-II, aacA4, $\operatorname{aad} A, \operatorname{aadB}, \operatorname{aad} E, \operatorname{aph} A 1, \operatorname{str} A, \operatorname{str} B, \operatorname{mef}(\mathrm{A}), \operatorname{mph}(\mathrm{B})$ and $q n r S$, and the results of aadA, strA and qnrS match the observation by Zhang et al. (2015). The above results indicated that ARG subtypes exhibited varied responses to mesophilic and thermophilic treatment (Fig. 1b and Table 1), which was also observed by Ma et al. (2011) and Zhang et al. (2015).

The reduction of ARGs during AD has been speculated to be associated with the blockage of their horizontal transfer pathways (Diehl and LaPara, 2010; Ma et al., 2011). Metagenomic analysis demonstrated that the abundance of mobilome including integrons, insert sequences and plasmids in thermophilic sludge was lower than that in mesophilic sludge (Fig. 2), suggesting lower horizontal transfer potential for ARGs under thermophilic conditions. Integrons, usually located in transposons or plasmids (Guerin et al., 2009), are important genetic elements for ARG recombination, and can acquire and express exogenous ARGs embedded within gene cassettes to accelerate their transfer (Stokes and Hall, 1989). As the most abundant integron in environmental bacteria (Stalder et al., 2014), intI1 has been suggested as a proxy for antibiotic pollution (Gillings et al., 2015; Aydin et al., 2015). In this study, all integron related sequences in sludge metagenomes belonged to intI1 and their abundances moderately decreased after temperature increase. Two efflux (tet(A) and $\operatorname{tet}(\mathrm{G}))$ and one ribosomal protection $($ tet $(\mathrm{Q}))$ tetracycline resistance genes were positively correlated with intI1, which was in accordance with the previous study on an oxytetracycline production wastewater treatment system, expect for tet(Q) (Liu et al., 2012). Neither tet(A) nor $\operatorname{tet}(\mathrm{G})$ have been detected as gene cassettes of intI1 (Partridge et al., 2009). However, tet(A) has been found to coexist with intI1 in conjugative plasmids (L'Abee-Lund and Sorum, 2001; Agerso and Sandvang, 2005), whereby they can be easily co-transferred into recipients, while tet $(G)$ has been found on the pattern 3 insertion sequence common region, a newly highlighted complex integron element usually linked to intI1 (Toleman et al., 2006).

Both ISs and plasmids are bacterial genetic elements responsible for the transfer of ARGs between different bacterial cells (Aminov, 2011). Compared with integrons, the two mobile elements had high diversity in the mesophilic and thermophilic sludge. After temperature increase, their abundances also decreased, and their compositions showed evident shifts (Figs. S5, S6 and S7), which might be driven by the succession of anaerobic microbial communities. For example, ISEnca1 of the mesophilic hydrolyticfermentative bacterium Enterococcus (Chen et al., 2006) decreased together with its host, while ISCth5 and ISPeth3, which belong to thermophilic hydrolytic-fermentative Clostridium thermocellum (Wilson et al., 2013) and thermophilic syntrophic propionate-oxidizing bacterium Pelotomaculum thermopropionicum
(Imachi et al., 2002), respectively, were detected with high abundances in the thermophilic sludge (Fig. S5). Similarly, plasmids p5482, p04 and pMUR050 found in mesophilic bacterial genera Bacteroides, Bacillus, and Escherichia (Xu et al., 2003; Gonzalez-Zorn et al., 2005), respectively, were decreased, while plasmid pTLIE01 originating from Thermovirga (Goeker et al., 2012), a thermophilic amino-acid-degrading bacterium (Dahle and Birkeland, 2006), was enriched more than 100-fold after the temperature increase.

The shift in the diversities of ISs and plasmids might impact the transferability of ARGs. Through coupling profile analysis between ARGs and plasmids, the dominant driver of DNA exchange in prokaryotes (Sorensen et al., 2005), a greater number of ARGs were found located in plasmids in the mesophilic sludge than those in the thermophilic sludge (Tables S5 and S6). The coupling of several resistance subtypes, including $\operatorname{tet}(\mathrm{X}), \operatorname{tet}(\mathrm{G}), \operatorname{tet}(33), \operatorname{erm}(\mathrm{G})$ and cml_e1, whose abundances decreased over the transition period, with plasmids also lost after temperature increase, suggesting the decreased transferability for these ARGs under thermophilic conditions. While for the enriched resistance gene aacA4, its coupling to plasmid occurred in the thermophilic sludge, suggesting higher transfer possibility of this gene through plasmid conjugation under thermophilic conditions. Thus, the lower availability of mobilomes including integrons, insert sequences and plasmids in thermophilic sludge might be partly responsible for the decreased abundance of ARGs.

On the other hand, it is known that the mesophilic anaerobic bacterial community is very different from the thermophilic one, which is characterized by a relatively low diversity (Sasak et al., 2011; Tian et al., 2015). Such a shift in bacterial community during the transition period might directly impact the vertical transfer of ARGs. Through network analysis, it was possible to assign the possible hosts for many targeted ARGs (Li et al., 2015; Ju et al., 2016). For example, sulfate-reducing Desulfobulbus, chloratereducing Dechloromonas and thermophilic fermentative EM3 were determined to be the possible hosts of tet $(\mathrm{L}), \operatorname{mef}(\mathrm{A})$ and $M p h(B)$, respectively. Total abundance of the 18 bacterial genera, which were suggested as the possible hosts for 13 ARGs, was decreased by close to 50\% after temperature increase, suggesting that decreased vertical transferability of resistance genes might also be an important mechanism of resistome reduction.

The hosts of tet(X) and aadE have been verified in previous studies (Table S8). Although recently also found in aerobic Sphingobacterium sp. (Ghosh et al., 2009b) and some Enterobacteriaceae and Pseudomonadaceae strains (Leski et al., 2013), the host diversity of tet(X) is relatively low (Chopra and Roberts, 2001), being mainly carried by Bacteroides (Guiney et al., 1984; Bartha et al., 2011; de Vries et al., 2011; Forslund et al., 2013). As described previously (Tian et al., 2015), Bacteroides was the dominant fermentative bacteria in mesophilic sludge, and experienced fast decline after temperature increase because all species of this genus are mesophilic (Garrity et al., 2004). At the same time, tet(X) has not yet been proved to be horizontally transferred to other strains (Ghosh et al., 2009b), in spite of the fact that it has been linked with a variety of mobile genetic elements (Guiney et al., 1984; Robillard et al., 1985; Shoemaker et al., 1986; Ghosh et al., 2009b). Therefore, the high reduction efficiency of tet $(\mathrm{X})$ during thermophilic $\mathrm{AD}$ could be attributed to the elimination of its bacterial host by the high temperature. It is interesting that aadE and Haloplasm rebounded after the temperature increase (Table S8 and Fig. S3). aadE is reported to be harbored by Haloplasma (Forslund et al., 2013), whose only type species, Haloplasma contractile, is mesophilic (Antunes et al., 2008). It is possible that some unknown thermophilic species in $\mathrm{Hal}$ oplasma might be responsible for the observed relevance between aadE and Haloplasma. In addition to the aadE gene, some aminoglycoside resistance genes also increased after the temperature 
hike (Table 1, Fig. S3), and significant correlations existed between the eight aminoglycoside resistance genes themselves (Fig. 4, Table S9), which might be attributed to the coexistence of aminoglycoside resistance genes in bacterial genomes (Karczmarczyk et al., 2011; Cain and Hall, 2012). Thus, co-selection might play an important role in their dissemination during the transition period.

It should be noted that the suggested hosts shown in Table S8 may not be consistent with their reported hosts, which was also observed by Li et al. (2015) using the same network analysis method. The inconsistency might be due to the fact that the reported hosts of ARGs have mainly been isolated from clinical settings, which differ from environmental bacteria (Sommer et al., 2009; Forsberg et al., 2014). To further validate the co-occurrence relationships revealed by network analysis, additional research is required to isolate bacterial hosts of ARGs from various environments. Furthermore, new techniques, such as functional metagenomics that allow direct linkage of detected ARGs with their potential hosts (Forsberg et al., 2014; Udikovic-Kolic et al., 2014), could be employed to better understand the role of vertical gene transfer in the dissemination of ARGs. On the other hand, metagenomic sequencing or qPCR used for the detection of ARGs cannot distinguish ARGs from live or dead cells in digested sludge, which may partially distort the temporal and spatial patterns of the detected ARGs. Also, a greater number of sludge samples for metagenomic analysis are needed to validate the result of this study.

\section{Conclusions}

This study showed a decrease in the total abundance of ARGs in anaerobic sludge treating sewage sludge after the increase of digestion temperature from mesophilic to thermophilic. Together with the decrease of resistome, the mobilome and potential bacterial hosts of ARGs in anaerobic digested sludge were also decreased after temperature increase, suggesting that the lower level of ARGs in the thermophilic sludge might be associated with the decrease in their horizontal and vertical transfer abilities. Based on these results, sludge treatment technologies like thermophilic $A D$, which can effectively remove the mobile genetic elements and bacterial hosts of ARGs, are recommended for the treatment of sewage sludge in full-scale WWTPs to limit the release of ARGs into the environment.

\section{Acknowledgments}

This study was supported by the National Natural Scientific Foundation of China (NSFC: 21437005; 21277162) and the Ministry of Science and Technology, People's Republic of China (2013DFG50150). We thank Dr. Miaomiao Liu for technical support.

\section{Appendix A. Supplementary data}

Supplementary data related to this article can be found at http:// dx.doi.org/10.1016/j.watres.2016.04.031.

\section{References}

Agerso, Y., Sandvang, D., 2005. Class 1 integrons and tetracycline resistance genes in Alcaligenes, Arthrobacter, and Pseudomonas spp. isolated from pigsties and manured soil. Appl. Environ. Microbiol. 71 (12), 7941-7947.

Aminov, R.I., 2011. Horizontal gene exchange in environmental microbiota. Front. Microbiol. 2, 158.

Antunes, A., Rainey, F.A., Wanner, G., Taborda, M., Paetzold, J., Nobre, M.F., da Costa, M.S., Huber, R., 2008. A new lineage of halophilic, wall-less, contractile bacteria from a brine-filled deep of the Red Sea. J. Bacteriol. 190 (10), 3580-3587.

Appels, L., Baeyens, J., Degreve, J., Dewil, R., 2008. Principles and potential of the anaerobic digestion of waste-activated sludge. Prog. Energy Combust. Sci. 34
(6), 755-781.

Auerbach, E.A., Seyfried, E.E., McMahon, K.D., 2007. Tetracycline resistance genes in activated sludge wastewater treatment plants. Water Res. 41 (5), 1143-1151.

Aydin, S., Ince, B., Ince, O., 2015. Development of antibiotic resistance genes in microbial communities during long-term operation of anaerobic reactors in the treatment of pharmaceutical wastewater. Water Res. 83, 337-344.

Bartha, N.A., Soki, J., Edit, U., Nagy, E., 2011. Investigation of the prevalence of tetQ. tetX and tetX1 genes in Bacteroides strains with elevated tigecycline minimum inhibitory concentrations. Int. J. Antimicrob. Agents 38 (6), 522-525.

Cain, A.K., Hall, R.M., 2012. Evolution of a multiple antibiotic resistance region in IncHI1 plasmids: reshaping resistance regions in situ. J. Antimicrob. Chemother. 67 (12), 2848-2853.

Chen, Y.G., Qu, T.T., Yu, Y.S., Zhou, J.Y., Li, L.J., 2006. Insertion sequence ISEcp1-like element connected with a novel $\operatorname{aph}\left(2^{\prime}\right)$ allele $\operatorname{aph}\left(2^{\prime}\right.$-le conferring high-level gentamicin resistance and a novel streptomycin ad enylyltransferase gene in Enterococcus. J. Med. Microbiol. 55 (Pt 11), 1521-1525.

Chopra, I., Roberts, M., 2001. Tetracycline antibiotics: mode of action, applications, molecular biology, and epidemiology of bacterial resistance. Microbiol. Mol. Biol. Rev. 65 (2), 232-260.

Dahle, H., Birkeland, N.K., 2006. Thermovirga lienii gen. nov., sp nov., a novel moderately thermophilic, anaerobic, amino-acid-degrading bacterium isolated from a North Sea oil well. Int. J. Syst. Evol. Microbiol. 56 (Pt 7), 1539-1545.

de Vries, L.E., Valles, Y., Agerso, Y., Vaishampayan, P.A., Garcia-Montaner, A. Kuehl, J.V., Christensen, H., Barlow, M., Francino, M.P., 2011. The gut as reservoir of antibiotic resistance: microbial diversity of tetracycline resistance in mother and infant. PLoS One 6 (6), e21644.

Deng, Y., Jiang, Y.H., Yang, Y., He, Z., Luo, F., Zhou, J., 2012. Molecular ecological network analyses. BMC Bioinformatics 13, 113.

Deng, Y., Zhang, P., Qin, Y., Tu, Q., Yang, Y., He, Z., Schadt, C.W., Zhou, J., 2016 Network succession reveals the importance of competition in response to emulsified vegetable oil amendment for uranium bioremediation. Environ. Microbiol. 18 (1), 205-218.

Diehl, D.L., LaPara, T.M., 2010. Effect of temperature on the fate of genes encoding tetracycline resistance and the integrase of class 1 integrons within anaerobic and aerobic digesters treating municipal wastewater solids. Environ. Sci. Technol. 44 (23), 9128-9133.

Forsberg, K.J., Patel, S., Gibson, M.K., Lauber, C.L., Knight, R., Fierer, N., Dantas, G., 2014. Bacterial phylogeny structures soil resistomes across habitats. Nature 509 (7502), 612-616.

Forslund, K., Sunagawa, S., Kultima, J.R., Mende, D.R., Arumugam, M., Typas, A., Bork, P., 2013. Country-specific antibiotic use practices impact the human gut resistome. Genome Res. 23 (7), 1163-1169.

Garrity, G.M., Bell, J.A., Lilburn, T.G., 2004. Phylum BXX. Bacteroidetes, Genus I. Bacteroides. Bergry's Manual of Systematic Bacteriology. Springer, New York.

Ghosh, S., Ramsden, S.J., LaPara, T.M., 2009a. The role of anaerobic digestion in controlling the release of tetracycline resistance genes and class 1 integrons from municipal wastewater treatment plants. Appl. Microbiol. Biotechnol. 84 (4), 791-796.

Ghosh, S., Sadowsky, M.J., Roberts, M.C., Gralnick, J.A., LaPara, T.M., 2009b. Sphingobacterium sp. strain PM2-P1-29 harbours a functional tet(X) gene encoding for the degradation of tetracycline. J. Appl. Microbiol. 106 (4), 1336-1342.

Gillings, M.R., Gaze, W.H., Pruden, A., Smalla, K., Tiedje, J.M., Zhu, Y.G., 2015. Using the class 1 integron-integrase gene as a proxy for anthropogenic pollution. ISME J. 9 (6), 1269-1279.

Goeker, M., Saunders, E., Lapidus, A., Nolan, M., Lucas, S., Hammon, N., Deshpande, S., Cheng, J.F., Han, C., Tapia, R., Goodwin, L.A., Pitluck, S., Liolios, K., Mavromatis, K., Pagani, I., Ivanova, N., Mikhailova, N., Pati, A., Chen, A. Palaniappan, K., Land, M., Chang, Y.j., Jeffries, C.D., Brambilla, E.-M., Rohde, M., Spring, S., Detter, J.C., Woyke, T., Bristow, J., Eisen, J.A., Markowitz, V. Hugenholtz, P., Kyrpides, N.C., Klenk, H.P., 2012. Genome sequence of the moderately thermophilic, amino-acid-degrading and sulfur-reducing bacterium Thermovirga lienii type strain (Cas60314(T)). Stand. Genomic Sci. 6 (2), 230-239.

Gonzalez-Zorn, B., Catalan, A., Escudero, J.A., Teshager, T., Porrero, C., Moreno, M.A. 2005. Genetic basis for dissemination of armA. J. Antimicrob. Chemother. 56 (3), 583-585.

Guerin, E., Cambray, G., Sanchez-Alberola, N., Campoy, S., Erill, I., Da Re, S., Gonzalez-Zorn, B., Barbe, J., Ploy, M.C., Mazel, D., 2009. The SOS response controls integron recombination. Science 324 (5930), 1034.

Guiney, D.G., Hasegawa, P., Davis, C.E., 1984. Expression in Escherichia coli of cryptic tetracycline resistance genes from bacteroides R plasmids. Plasmid 11 (3), 248-252.

Horvath, S., Dong, J., 2008. Geometric interpretation of gene coexpression network analysis. PLoS Comput. Biol. 4 (8), e1000117.

Hugenholtz, P., Pitulle, C., Hershberger, K.L., Pace, N.R., 1998. Novel division level bacterial diversity in a Yellowstone hot spring. J. Bacteriol. 180 (2), 366-376.

Imachi, H., Sekiguchi, Y., Kamagata, Y., Hanada, S., Ohashi, A., Harada, H., 2002. Pelotomaculum thermopropionicum gen. nov., sp nov., an anaerobic, thermophilic, syntrophic propionate-oxidizing bacterium. Int. J. Syst. Evol. Microbiol. 52 (Pt 5), 1729-1735.

Ju, F., Li, B., Ma, L.P., Wang, Y., Huang, D., Zhang, T., 2016. Antibiotic resistance genes and human bacterial pathogens: co-occurrence, removal, and enrichment in municipal sewage sludge digesters. Water Res. 91, 1-10.

Karczmarczyk, M., Abbott, Y., Walsh, C., Leonard, N., Fanning, S., 2011. Characterization of multidrug-resistant Escherichia coli isolates from animals presenting 
at a university veterinary hospital. Appl. Environ. Microbiol. 77 (20), $7104-7112$.

Koike, S., Krapac, I.G., Oliver, H.D., Yannarell, A.C., Chee-Sanford, J.C., Aminov, R.I., Mackie, R.I., 2007. Monitoring and source tracking of tetracycline resistance genes in lagoons and groundwater adjacent to swine production facilities over a 3-year period. Appl. Environ. Microbiol. 73 (15), 4813-4823.

Kristiansson, E., Fick, J., Janzon, A., Grabic, R., Rutgersson, C., Weijdegard, B., Soderstrom, H., Larsson, D.G.J., 2011. Pyrosequencing of antibiotic-contaminated river sediments reveals high levels of resistance and gene transfer elements. PLoS One 6 (2), e17038.

L'Abee-Lund, T.M., Sorum, H., 2001. Class 1 integrons mediate antibiotic resistance in the fish pathogen Aeromonas salmonicida worldwide. Microb. Drug Resist. 7 (3), 263-272.

Leski, T.A., Bangura, U., Jimmy, D.H., Ansumana, R., Lizewski, S.E., Stenger, D.A. Taitt, C.R., Vora, G.J., 2013. Multidrug-resistant tet(X)-containing hospital isolates in Sierra Leone. Int. J. Antimicrob. Agents 42 (1), 83-86.

Li, B., Yang, Y., Ma, L., Ju, F., Guo, F., Tiedje, J.M., Zhang, T., 2015. Metagenomic and network analysis reveal wide distribution and co-occurrence of environmental antibiotic resistance genes. ISME J. 9 (11), 2490-2502.

Liu, M., Ding, R., Zhang, Y., Gao, Y., Tian, Z., Zhang, T., Yang, M., 2014. Abundance and distribution of Macrolide-Lincosamide-Streptogramin resistance genes in an anaerobic-aerobic system treating spiramycin production wastewater. Water Res. 63, 33-41.

Liu, M., Zhang, Y., Yang, M., Tian, Z., Ren, L., Zhang, S., 2012. Abundance and distribution of tetracycline resistance genes and mobile elements in an oxytetracycline production wastewater treatment system. Environ. Sci. Technol. 46 (14), $7551-7557$.

Ma, Y., Wilson, C.A., Novak, J.T., Riffat, R., Aynur, S., Murthy, S., Prudens, A., 2011 Effect of various sludge digestion conditions on sulfonamide, macrolide, and tetracycline resistance genes and class I integrons. Environ. Sci. Technol. 45 (18), 7855-7861.

Miao, Y., Liao, R., Zhang, X.X., Wang, Y., Wang, Z., Shi, P., Liu, B., Li, A., 2015. Metagenomic insights into $\mathrm{Cr}(\mathrm{VI})$ effect on microbial communities and functional genes of an expanded granular sludge bed reactor treating high-nitrate wastewater. Water Res. 76, 43-52.

Munck, C., Albertsen, M., Telke, A., Ellabaan, M., Nielsen, P.H., Sommer, M.O.A., 2015. Limited dissemination of the wastewater treatment plant core resistome. Nat. Commun. 6, 8452.

Partridge, S.R., Tsafnat, G., Coiera, E., Iredell, J.R., 2009. Gene cassettes and cassette arrays in mobile resistance integrons. FEMS Microbiol. Rev. 33 (4), 757-784.

Pei, R., Kim, S.C., Carlson, K.H., Pruden, A., 2006. Effect of river landscape on the sediment concentrations of antibiotics and corresponding antibiotic resistance genes (ARG). Water Res. 40 (12), 2427-2435.

Robillard, N.J., Tally, F.P., Malamy, M.H., 1985. Tn4400, a compound transposon isolated from Bacteroides fragilis, functions in Escherichia coli. J. Bacteriol. 164 (3), 1248-1255.

Sasak, D., Hori, T., Haruta, S., Ueno, Y., Ishii, M., Igarashi, Y., 2011. Methanogenic pathway and community structure in a thermophilic anaerobic digestion process of organic solid waste. J. Biosci. Bioeng. 111 (1), 41-46.
Shoemaker, N.B., Getty, C., Gardner, J.F., Salyers, A.A., 1986. Tn4351 transposes in Bacteroides spp. and mediates the integration of plasmid R751 into the Bacteroides chromosome. J. Bacteriol. 165 (3), 929-936.

Sommer, M.O.A., Dantas, G., Church, G.M., 2009. Functional characterization of the antibiotic resistance reservoir in the human microflora. Science 325 (5944), $1128-1131$.

Sorensen, S.J., Bailey, M., Hansen, L.H., Kroer, N., Wuertz, S., 2005. Studying plasmid horizontal transfer in situ: a critical review. Nat. Rev. Microbiol. 3 (9), 700-710.

Stalder, T. Barraud, O., Jove, T. Casellas, M. Gaschet, M., Dagot, C., Ploy, M.C., 2014 Quantitative and qualitative impact of hospital effluent on dissemination of the integron pool. ISME J. 8 (4), 768-777.

Stokes, H.W., Hall, R.M., 1989. A novel family of potentially mobile DNA elements encoding site-specific gene-integration functions: integrons. Mol. Microbiol. 3 (12), 1669-1683.

Su, J.Q., Wei, B., Ouyang, W.Y., Huang, F.Y., Zhao, Y., Xu, H.J., Zhu, Y.G., 2015. Antibiotic resistome and its association with bacterial communities during sewage sludge composting. Environ. Sci. Technol. 49 (12), 7356-7363.

Szczepanowski, R., Linke, B., Krahn, I., Gartemann, K.H., Gützkow, T., Eichler, W., Pühler, A., Schlüter, A., 2009. Detection of 140 clinically relevant antibioticresistance genes in the plasmid metagenome of wastewater treatment plant bacteria showing reduced susceptibility to selected antibiotics. Microbiology 155 (Pt 7), 2306-2319.

Tian, Z., Zhang, Y., Li, Y.Y. Chi, Y.Z., Yang, M., 2015. Rapid establishment of thermophilic anaerobic microbial community during the one-step startup of thermophilic anaerobic digestion from a mesophilic digester. Water Res. 69, 9-19.

Toleman, M.A., Bennett, P.M., Walsh, T.R., 2006. ISCR elements: novel genecapturing systems of the 21st century? Microbiol. Mol. Biol. Rev. 70 (2), $296-316$.

Udikovic-Kolic, N., Wichmann, F., Broderick, N.A., Handelsman, J., 2014. Bloom of resident antibiotic-resistant bacteria in soil following manure fertilization. Proc. Natl. Acad. Sci. U. S. A. 111 (42), 15202-15207.

Wilson, C.M., Rodriguez Jr., M., Johnson, C.M., Martin, S.L., Chu, T.M., Wolfinger, R.D., Hauser, L.J., Land, M.L., Klingeman, D.M., Syed, M.H., Ragauskas, A.J., Tschaplinski, T.J., Mielenz, J.R., Brown, S.D., 2013. Global transcriptome analysis of Clostridium thermocellum ATCC 27405 during growth on dilute acid pretreated Populus and switchgrass. Biotechnol. Biofuels 6 (1), 179.

Xu, J., Bjursell, M.K., Himrod, J., Deng, S., Carmichael, L.K., Chiang, H.C., Hooper, L.V., Gordon, J.I., 2003. A genomic view of the human-Bacteroides thetaiotaomicron symbiosis. Science 299 (5615), 2074-2076.

Yang, Y., Li, B., Ju, F., Zhang, T., 2013. Exploring variation of antibiotic resistance genes in activated sludge over a four-year period through a metagenomic approach. Environ. Sci. Technol. 47 (18), 10197-10205.

Zhang, T., Yang, Y., Pruden, A., 2015. Effect of temperature on removal of antibiotic resistance genes by anaerobic digestion of activated sludge revealed by metagenomic approach. Appl. Microbiol. Biotechnol. 99 (18), 7771-7779.

Zhang, X.X., Zhang, T., 2011. Occurrence, abundance, and diversity of tetracycline resistance genes in 15 sewage treatment plants across China and other global locations. Environ. Sci. Technol. 45 (7), 2598-2604. 